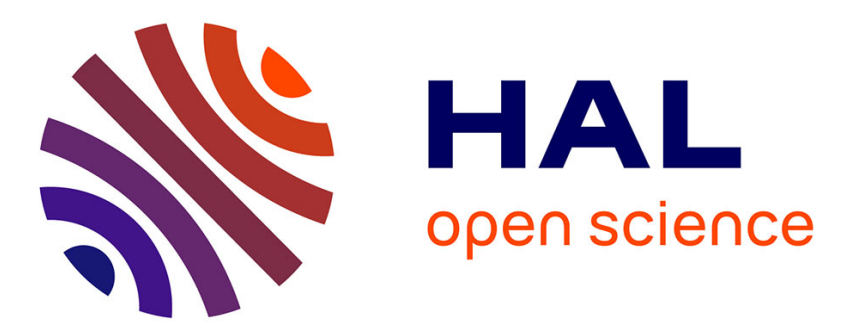

\title{
Coniferyl Alcohol Radical Detection by the Dirigent Protein At DIR6 Monitored by EPR
}

Camille Modolo, Lu Ren, Eric Besson, Viviane Robert, Stephane Gastaldi, Pierre Rousselot- Pailley, Thierry Tron

\section{- To cite this version:}

Camille Modolo, Lu Ren, Eric Besson, Viviane Robert, Stephane Gastaldi, et al.. Coniferyl Alcohol Radical Detection by the Dirigent Protein At DIR6 Monitored by EPR. ChemBioChem, 2021, 22 (6), pp.992-995. 10.1002/cbic.202000650 . hal-03121563

\section{HAL Id: hal-03121563 https://hal.science/hal-03121563}

Submitted on 24 Mar 2021

HAL is a multi-disciplinary open access archive for the deposit and dissemination of scientific research documents, whether they are published or not. The documents may come from teaching and research institutions in France or abroad, or from public or private research centers.
L'archive ouverte pluridisciplinaire HAL, est destinée au dépôt et à la diffusion de documents scientifiques de niveau recherche, publiés ou non, émanant des établissements d'enseignement et de recherche français ou étrangers, des laboratoires publics ou privés. 


\title{
Coniferyl alcohol radical detection by the dirigent protein AtDIR6 monitored by EPR.
}

\author{
Camille Modolo, ${ }^{\text {a† }}$ Lu Ren, ${ }^{\text {a† }}$ Eric Besson, ${ }^{\text {b }}$ Viviane Robert, ${ }^{\text {a }}$ Stéphane Gastaldi, ${ }^{\text {b }}$ Pierre Rousselot- \\ Pailley ${ }^{a^{*}}$ and Thierry Tron ${ }^{{ }^{*}}$.
}

[a] Dr. C. Modolo; Dr. L. Ren; Dr. V. Robert; Dr. P. Rousselot-Pailley, Dr. T. Ton.

Aix Marseille Univ, Centrale Marseille, CNRS, iSm2, France t

E-mail: pierre.rousselot-pailley@univ-amu.fr; thierry.tron@univ-amu.fr

[b] Dr. E. Besson; Dr. S. Gastaldi

Aix Marseille Univ, CNRS, ICR, France

Supporting information for this article is given via a link at the end of the document.

\begin{abstract}
Plant dirigent proteins (DIRs) control the stereo-selectivity of the monolignol coniferyl alcohol radical coupling reaction. The main mechanistic hypothesis on this chemo- and stereo-selective reaction invokes a binding of coniferyl alcohol radical substrates in the dirigent protein active site so that only one enantiomeric form can be produced Here, the influence of the Arabidopsis thaliana AtDIR6 protein on the transient coniferyl alcohol radical is studied by EPR. We show that AtDIR6 stabilizes coniferyl alcohol radicals prior to directing their coupling towards the formation of (-)-pinoresinol.
\end{abstract}

\section{Introduction}

Coniferyl, $p$-coumaryl and sinapyl alcohols belong to the monolignol family of plant secondary metabolites (Scheme 1). Monolignols are building blocks for the biosynthesis of natural product such as lignans and neo-lignans ${ }^{1,2}$ as well as precursors in lignin biosynthesis. ${ }^{3}$

A
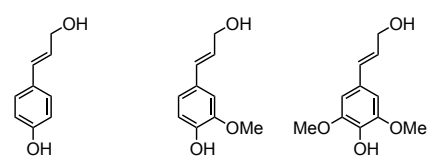

B

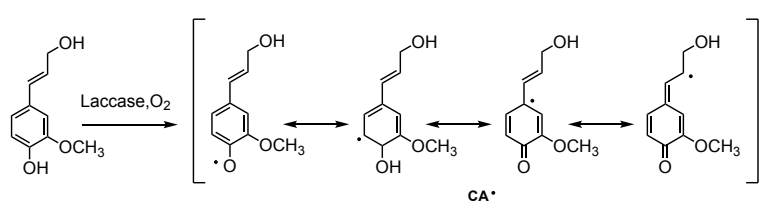

c

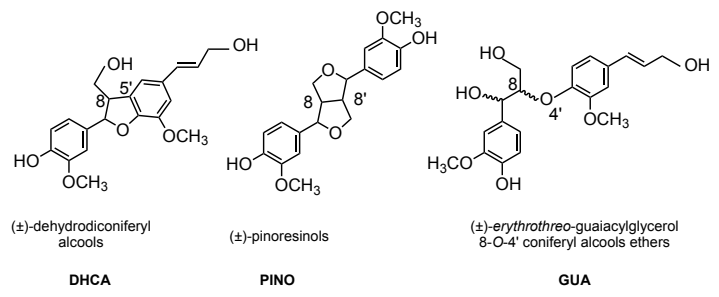

Scheme 1. Scheme 1: Monolignols, lignans and neo-lignans. A: Chemical structure of main monolignols; $\mathrm{B}$ : resonance mesomers of the coniferyl radical $\left(\mathrm{CA}^{*}\right)$ produced upon oxidation; C: chemical structure of the initial dimers obtained from coniferyl alcohol oxidation.

In lignan biosynthesis it is generally accepted that the initial oxidation step is performed by an oxidative enzyme such as laccase or peroxidase that generates a resonance stabilized 4 -vinylphenoxyl radical. ${ }^{4}$ In the case of coniferyl alcohol (CA) the radical $\left(\mathrm{CA}^{\circ}\right)$ dimerises to form pinoresinol (PINO), dehydrodiconiferyl alcohol (DHCA) and erythro/threo guiacylglycerol (GUA) dimers (Scheme $1 \mathrm{C}$ ). In vitro, each of the above mentioned dimers is produced in a racemic form. In 1997, Lewis and co-workers have identified in the higher plant Forsythia intermedia a protein factor apparently devoid of oxidative centre capable of influencing the fate of the bimolecular phenoxy radical coupling reaction in leading to the exclusive formation of (+)-pinoresinol. ${ }^{5}$ This protein factor has been named Dirigent Protein (DIR). Following the discovery of the dirigent protein FiDIR1 from $F$. intermedia an enantiocomplementary DIR AtDIR6 leading to the formation of the ()-pinoresinol has been identified in Arabidospis thaliana. ${ }^{2 b, 6}$ a,b Since their initial description, many genes potentially encoding stereo-selective PINO-forming proteins have been reported in different plant genomes.5, 7 Additionally, beyond the biosynthesis of pinoresinol a case of DIR activity has been described for a cotton protein conferring atropo-selectivity in the formation of gossypol (a plant defence compound).8,9,10 Recently, evidences for proteins in the dirigent family functioning as part of the machinery that builds extracellular lignin-based structures have been obtained. ${ }^{11}$ The discovery of DIRs has immediately led to a questioning about a proteinpromoted radical coupling mechanism. It has been proposed that $\mathrm{CA}^{\cdot}$ rather than the coniferyl alcohol itself is the true substrate of DIRs. This hypothesis results essentially from two observations: i) the ee of PINO depends both on DIR concentration and on the oxidation rate of the CA (equivalent to the apparent concentration of the $\mathrm{CA}^{\circ}$ at steady state), and ii) the respective affinities of FiDIR1 for CA $\left(K_{d}=37010^{-6} \mathrm{M}\right)$ and its radical $\left(K_{d}=1010^{-9} \mathrm{M}\right)$ evaluated from a kinetic model in which the DIR-mediated coupling of $\mathrm{CA}^{\circ}$ competes with uncontrolled coupling. ${ }^{12}$ Crystal structures of two enantiocomplementary DIRs, i.e, (+)-pinoresinol-forming pea DRR206 and (-)-pinoresinol forming AtDIR6, have been recently obtained. ${ }^{13,14}$ The overall structure of both DIRs consists in an homo-trimer of a $\beta$-barrel unit in which a potential binding pocket clustering residues important for the selectivity has been identified. To illustrate the proposed DIR/CA ${ }^{*}$ interaction in the mediated stereoselective coupling manual docking has been used to fit properly oriented radical molecules. ${ }^{13,14}$ However, so far there has been no direct experimental evidence revealing the interaction between a DIR protein and a radical.

Electron Paramagnetic Resonance (EPR) is clearly the technique of choice for the direct observation of a radical. A 
signal of $\mathrm{CA}^{*}$ obtained from UV irradiation $(310 \mathrm{~nm})$ of the coniferyl alcohol has been observed by low-temperature EPR in the mid-seventies. ${ }^{15}$ From this study, it comes that the unpaired electron is delocalized over the entire molecule and that the half-life of the radical is approximately $10 \mathrm{~s}$ at $223 \mathrm{~K}$. Therefore, one can easily predict a life time too short to enable a direct observation of a $\mathrm{CA}^{\circ}$ at room temperature unless an external component stabilizes it through supramolecular interactions as observed with inorganic porous materials such as silicas or zeolites. ${ }^{16,17}$ Here, we investigated the potential of the (-)-pinoresinol forming dirigent protein AtDIR6 in the stabilization of the coniferyl radical. CA/AtDIR6 relationships were examined by X-band EPR at room temperature after generating phenoxyl radicals in situ (i.e. in the EPR cavity). Our results clearly evidence an increase of the life time (i. e. a stabilization) of a phenoxyl radical in the presence of the dirigent protein.

\section{Results and discussion}

The demonstration of the dirigent activity of DIRs has required the use of a chemical (e.g. ammonium persulfate) or an enzymatic (e.g. laccase) oxidant. ${ }^{5}$ In order to simplify the study, we decided to replace the oxidative part of the system by a simple UV light irradiation (in fact an unfiltered white light) which should provide as well a clean formation of phenoxyl radicals. ${ }^{15}$ This approach enables to minimize the number of paramagnetic species and to control the triggering of the process in the EPR cavity.

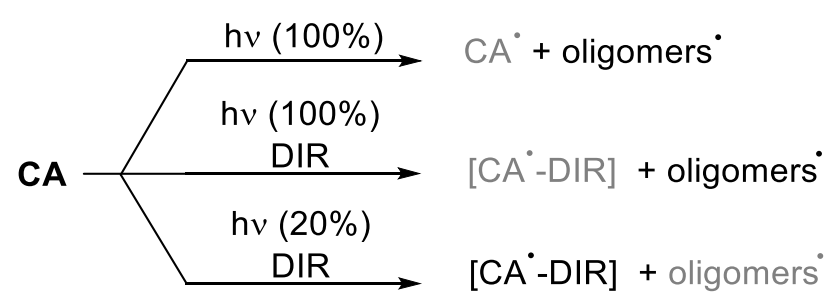

Scheme 2: radicals from the irradiation of an aqueous solution of CA. In grey minor contributors to the EPR signal.

UV light being a relatively high energetic source, we first verified if under our experimental conditions the light source would generate a radical onto the AtDIR6 protein itself. Under continuous white light $(200 \mathrm{~W}, 200<\lambda<800 \mathrm{~nm})$ irradiation of the cavity of the EPR spectrometer no signal was observed for a sample of AtDIR6. Therefore, under these conditions the light source is not generating any detectable radical onto the protein. In order to assess the formation of a $\mathrm{CA}^{*}$ under irradiation of a CA solution, preliminary spin trapping experiments were performed with 5,5-dimethyl-1-pyrroline $N$ oxide (DMPO) which, contrary to spin-traps used in previous studies, ${ }^{15,} 18$ traps efficiently both carbon- and oxygencentered radicals. After 10 min irradiation, examination of the EPR spectrum revealed only the addition of carbon centeredradicals onto DMPO (HFC $a_{H}=21.1$ and $24.3 \mathrm{G}$ ) which confirms the radical delocalization on the vinyl moiety (see Figure SI1). This result is in agreement with previous theoretical calculations supporting a radical delocalization on the whole CA molecule. ${ }^{4}$ Because of its fugacious character, no signal of a phenoxyl radical should be directly observable at room temperature during the constant UV-irradiation of an aqueous solution of $\mathrm{CA} .{ }^{15}$ However, irradiation of a CA solution at $100 \%$ of the light power eventually generated a broad EPR feature $(g=2.005)$ corresponding to signals of a mixture of radicals in different environments typical of unterminated branched phenolic polymers. ${ }^{19}$ In order to avoid masking a potentially resolved signal of a stabilized $\mathrm{CA}^{\circ}$, the light power was adjusted until the complete disappearance of the broad signal. This was obtained with a light power set at $20 \%$ of the nominal power of the light source. As set, no signal of a radical is observable from a CA solution under constant UV-irradiation at room temperature (Fig. 1 dotted blue line). To the contrary, when CA and AtDIR6 were mixed and photo irradiated together a signal centered at $g=2.004$ (peak to peak signal width $11 \mathrm{G}$ ) typical for a phenoxyl radical $15,17,20$ was recorded (Fig. 1 solid blue line). Moreover, both the shape and the $g$ value of this signal are similar to those we observed for a photo generated coniferyl alcohol radical adsorbed on SBA-15 silica after 10 min of irradiation (see Figure SI2). The signal of the radical obtained in the presence of AtDIR6 appears therefore consistent with that of a coniferyl alcohol radical. The fact that the intensity of the signal increased as the initial amount of coniferyl alcohol increased supports further the conclusion that the observed radical arises from $\mathrm{CA}$. The signal of a $\mathrm{CA}^{\circ}$ arose as light was turned on and faded away rapidly within the time scale of few scans with a $t_{1 / 2}$ estimated around $2 \mathrm{~min}$. The amplitude and the limited persistence of the signal can be interpreted as consequences of the evolution of a $\mathrm{CA}^{*}$ which although stabilized is still capable of reacting eventually forming dimers and further oligomers. Possibilities of formation of radicals generated by irradiation in relation to different reaction conditions (i.e. light power, presence or absence of DIR) are summarized in Scheme 2.

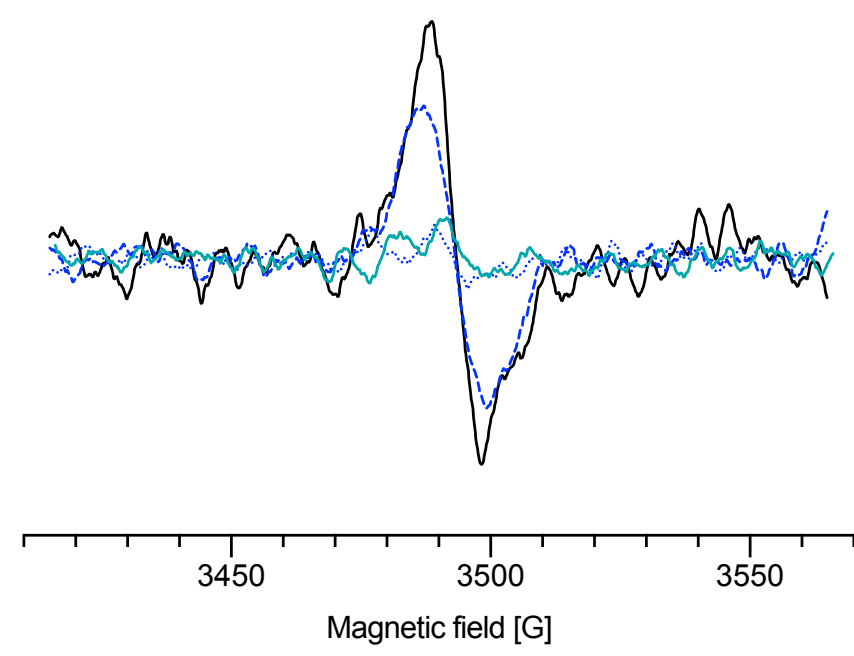

Figure 1: Room temperature EPR spectra of coniferyl alcohol and AtDIR6 under continuous photo-irradiation. Deoxygenated acetate buffered $\left(10010^{-3} \mathrm{M} \mathrm{pH}\right.$ 5.5) $0.7510^{-3} \mathrm{M}$ (dashed blue line) or $1.610^{-3} \mathrm{M}$ (solid black line) solutions of $\mathrm{CA}$ in the presence of $0.510^{-3} \mathrm{M}$ AtDIR6. Controls: $1.610^{-3} \mathrm{M}$ of CA (dotted blue line); $0.3510^{-3} \mathrm{M}$ AtDIR6 (solid green line). Irradiation conditions: white light $(200<\lambda<800 \mathrm{~nm})$ lamp $200 \mathrm{~W}, 20 \%$ of nominal power. Microwave Power: $0.6325 \mathrm{~mW}$; Modulation amplitude: $1 \mathrm{G}$; Receiver Gain : $90 \mathrm{~dB}$

Working with a lower concentration of AtDIR6 $\left(0.110^{-3} \mathrm{M}\right)$ led to a modest decrease of the $\mathrm{CA}^{\bullet}$ signal intensity (Fig. SIXX). In order to further study the dependence on DIR for the detection of a $\mathrm{CA}^{*}$ we photo-irradiated a CA mixture containing lysozyme $\left(0.510^{-3} \mathrm{M}\right.$ in acetate buffer $\left.\mathrm{pH} 5.5\right)$ instead of AtDIR6 in a control experiment. In these conditions, no signal was observed thus confirming the specific role of the DIR in the stabilization of the coniferyl alcohol radical. Eventually, CA was replaced by sinapyl alcohol (Scheme 1) on which DIRs are known to have no control. ${ }^{1,5,6}$ As no significant EPR signal 
was observed (Fig. SI3) we conclude on the specificity of AtDIR6 for the stabilization of the $\mathrm{CA}^{\circ}$. Altogether, our results represent the first direct experimental evidence of a stabilization of a phenoxyl radical by a DIR.

Figure 2: Separation of coniferyl alcohol dimerization products by HPLC. Oxidation of CA under irradiation (UV light) in the absence (red trace) or presence (black trace) of AtDIR6 (conditions are those of Fig. 1). BEN =

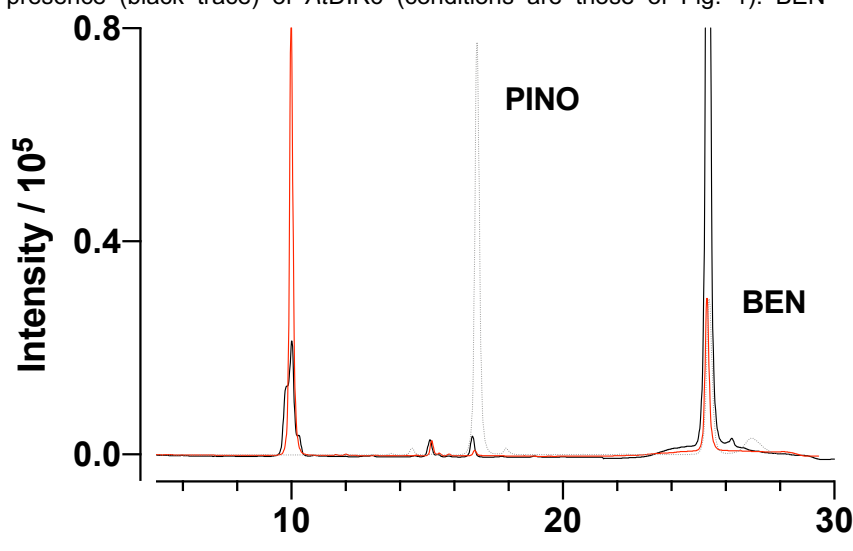

time / $\min$

benzophenone (internal reference); PINO: pinoresinol standard (dotted grey trace overlay); $\lambda$ detect $280 \mathrm{~nm}$

All along this study, the oxidative enzymatic reaction was replaced by a photochemical homolysis of the $\mathrm{O}-\mathrm{H}$ phenolic bond so it remained to control that the fate of the reaction in the presence of DIR was the very same as in a biocatalysis experiment. Thus, immediately following photo irradiation, reaction mixtures $( \pm$ DIR) were subjected to HPLC analysis. Chromatograms are presented in Figure 2. These chromatograms are very similar to those obtained from biocatalysis, i.e. with laccase as oxidant of CA (Fig. SI4). In particular, the ratio of areas PINO/DHA varies from 0.3 in the absence of AtDIR6 to 1.7 in its presence highlighting the influence of the dirigent protein (from 0.1 to 1.5 for the biocatalysis of Fig. SI4). The peak corresponding to the PINO formed was recovered and the ee was evaluated from the separation on a chiral column (see SI). As with the combination of laccase and AtDIR6, the (-)-pinoresinol was obtained with an ee of $88 \%$. So, under photo-irradiation AtDIR6 not only stabilizes $\mathrm{CA}^{-}$but seems to retain its capability to direct their coupling towards the formation of (-)pinoresinol. It must be underlined here that the formation of ()-pinoresinol validates a posteriori the choice of irradiation conditions which make it-possible the generation of a $\mathrm{CA}^{\circ}$ while reducing the formation of polymeric adducts.

\section{Conclusions}

Postulated for years, the stabilization of the $\mathrm{CA}^{\bullet}$ by a DIR is directly experimentally observed here for the first time. Using controlled photo-irradiation of coniferyl alcohol to generate a $\mathrm{CA}^{\circ}$ and room temperature EPR and HPLC to monitor the fate of the radical we demonstrate that the dirigent protein AtDIR6 is stabilizing the formed radical prior directing the coupling of radicals towards the formation of (-)-pinoresinol. The question on how the CA radical ends up in the coupling site of the protein remains pending. The synthesis of CA analogues and their study as mechanistic probes are currently under progress in our laboratories.

\section{Acknowledgements}

This study was supported by funds from the CNRS, Aix Marseille Universite (AMU), the Graduate School of Chemistry of AMU and from a grant from the Agence Nationale de la Recherche (ANR09-BLANC-0176). CM is a recipient of a fellowship from the Fondation Pierre Potier. LR is a recipient of a fellowship from the China Scholarship Council (201604490005). We thank Elise Courvoisier-Dezord from the Plateforme AVB (AMU): Analyse et Valorisation de la Biodiversité and Yolande Charmasson for help in the production of the recombinant AtDIR6 and Nicolas Vanthuyne for the determination of enantiomeric excesses. We also thank Marius Réglier for numerous stimulating discussions

${ }^{\dagger}$ these authors contributed equally to this work

Keywords: dirigent protein - radical - UV light • stereoselectivity•EPR

N.G. Lewis, L.B. Davin, Lignans: biosynthesis and function. In DHR Barton, K Nakanishi, O Meth-Cohn, eds, Comprehensive Natural Products Chemistry, 1999, Vol 1. Elsevier, London, 1999; pp 639-712.

a) S. Suzuki, T. Umezawa, J. Wood Sci. 2007 ,53, 273-284.

b) D. G. Vassão, K.-W. Kim, L. B. Davin, N. G. Lewis, Lignans (neolignans) and allyl/propenyl phenols: Biogenesis, structural biology, and biological/human health considerations. In Comprehensive Natural Products Chemistry II (C. Townsend and Y. Ebizuka eds.), Vol. 1: Structural Diversity I, Elsevier, Oxford, UK. 2010; pp 815-928

N.G. Lewis, E. Yamamoto, Annu. Rev. Plant Physiol. Plant Mol. Biol. $1990,41,455-496$.

${ }^{4}$ B. Durbeej, L. Eriksson, Holzforschung, 2003, 57, 59-61

L.B. Davin, H.-B. Wang, A.L. Crowell, D.L. Bedgar, D.M. Martin, S. Sarkanen, N.G. Lewis, Science. 1997, 275, 362-367.

6 a) B. Pickel, M.A. Constantin, J. Pfannstiel, J. Conrad, U. Beifuss, A. Schaller, Angew. Chem. Int. Ed. 2010, 49, 202-204.

b) K.-W. Kim, S.G. Moinuddin, K.M. Atwell, M. Costa, L.B. Davin, N.G.

Lewis, J. Biol. Chem. 2012, 287, 33957-33972

${ }^{7}$ a) Z.-Q. Xia, M. A. Costa, J. Proctor. L. B. Davin, N. G. Lewis, Phytochemistry. 2000, 55, 537-549.

b) M. K. Kim, J.-H. Jeon, L. B. Davin, N. G. Lewis, Phytochemistry. 2002 61, 311-322.

c) M. K. Kim, J.-H. Jeon, M. Fujita, L. B. Davin, N. G. Lewis, Plant Mol. Biol. 2002, 49, 199-214.

d) S. G. Ralph, S. Jancsik, J. Bohlmann, Phytochemistry. 2007, 68, 1975 1991

e) D.S. Dalisay, K.W. Kim, C. Lee, H. Yang, O. Rübel, B.P. Bowen, L.B Davin, N.G. Lewis, J. Nat. Prod. 2015, 78, 1231-1242.

f) H.K. Seneviratne, D.S. Dalisay, K.-W. Kim, S.G.A. Moinuddin, H. Yang, C.M. Hartshorn, L.B. Davin, N.G. Lewis, Phytochemistry. 2015, 113, $140-148$

g) C. Corbin, S. Drouet, L. Markulin, D. Anguin, E. Lainé, L. B. Davin,

J. R. Cort, N. G. Lewis, C. Hano, Plant. Mol. Biol. 2018, 97, 73-101

8 J. Liu, R. D. Stipanovic, A. Bell, L. S. Puckhaber, C. W. Magill, Phytochemistry. 2008, 69, 3038-3042.

9 I. Effenberger, B. Zhang, L. Li, Q. Wang, Y. Liu, I. Klaiber, J. Pfannstiel, Q. Wang, A. Schaller, Angew. Chem. Int. Ed. 2015, 54, 14660-14663.

10 I. Effenberger, M. Harport, J. Pfannstiel, I. Klaiber, A. Schaller, Appl. Microbiol. Biotechnol. 2017, 101, 2021-2032.

11 a) P. S. Hosmani, T. Kamiya, J. Danku, S. Naseer, N. Geldner, M. L. Guerinot, D. E. Salt, Proc. Natl. Acad. Sci. USA. 2013, 110, 14498-14503.

b) T. Kamiya, M. Borghi, P. Wang, J. M. Danku, L. Kalmbach, P. S. Hosmani, S. Naseer, T. Fujiwara, N. Geldner, D. E. Salt, Proc. Natl. Acad. Sci. USA.2015, 112, 10533-10538.

c) K. Uchida, T. Akashi, T. Aoki, Plant Cell Physiol. 2017, 58, 398-408.

d) Q. Meng, S. G. A. Moinuddin, S.-J. Kim, D. L. Bedgar, M. A. Costa, D.

G. Thomas, R. P. Young, C. A. Smith, J. R. Cort, L. B. Davin, N. G. Lewis, J. Biol. Chem. 2020, 295, 11584-11601.

12 S. C. Halls, L. B. Davin, D. M. Kramer, N. G. Lewis, Biochemistry. 2004 43, 2587-2595.

13 K.-W. Kim, C. A. Smith, M. D. Daily, J. R. Cort, L. B. Davin, N. G. Lewis, J. Biol. Chem. 2015, 290, 1308-1318.

14 R. Gasper, I. Effenberger, P. Kolesinski, B. Terlecka, E. Hofmann, A Schaller, Plant Physiol. 2016, 172, 2165-2175.

15 G. J. Smith, I. J. Miller, Aust. J. Chem. 1975, 28, 193-196.

16 C. Dol, G. Gerbaud, B. Guigliarelli, E. Bloch, S. Gastaldi, E. Besson, Phys. Chem. Chem. Phys., 2019, 21, 16337-16344 
17 N. J. Turro, X.-G. Lei, S. Jockusch, W. Li, Z. Liu, L. Abrams, M. F. Ottaviani, J. Org. Chem. 2002, 67, 2606-2618.

18 N. Deighton, G. J. McDougall, Phytochemistry ,1998, 48, 601-606

L. Munk, M. L. Andersen, A. S. Meyer, Enzyme Microb. Technol. 2017 106, 88-96

20 C. Dol, M. P. Bertrand, S. Gastaldi, E. Besson, Tetrahedron, 2016, 72

7744-7748. 


\section{Entry for the Table of Contents}

Insert graphic for Table of Contents here.

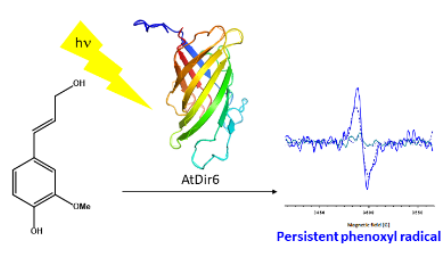

Direct observation of the radical of coniferyl alcohol in presence of Atdir6 under UV light irradiation at room temperature. 